\title{
Análisis de la evolución de la Balanza Comercial y del Producto InTerno Bruto en el Ecuador EN EL PERÍODO COMPRENDIDO ENTRE LOS AÑOS 2011-2015
}

\section{Analysis of the Trade Balance and Gross Domestic PRODUCT EVOLUTION IN ECUADOR} IN THE PERIOD BETWEEN THE YEARS 2011-2015

ZLATA BORSIC LABORDE

Correo electrónico: zdborsic@espe.edu.ec

\section{KAROL BENÍTEZ BURBANO}

Correo electrónico: knbenitez@espe.edu.ec

\section{RESUMEN}

El comportamiento de la balanza comercial es un elemento fundamental en la toma de decisiones económicas, financieras y sociales de los países; por lo tanto, se hace necesario tomar en consideración su comportamiento. Es por ello que en el presente estudio se exhiben los resultados obtenidos en la balanza comercial del Ecuador, todo esto con la finalidad de identificar el comportamiento de la balanza comercial en el país en estos últimos cinco ańos e identificar el porcentaje de participación de la balanza comercial respecto del Producto Interno Bruto en el Ecuador y el crecimiento tanto del PIB como de la balanza comercial.

Palabras clave: Balanza Comercial, Producto Interno Bruto.

\begin{abstract}
The demeanor of the trade balance is a fundamental element in the economic, financial and social decisions of the countries; therefore, it is necessary to take into consideration its behavior. This is why the present study shows the results obtained in the trade balance of Ecuador, with the purpose of identifying the demeanor of the trade balance in the country in the last five years, and identify the percentage of participation of the trade balance in Ecuador's gross domestic product.
\end{abstract}

Keywords: Trade Balance, Gross Domestic Product. 


\section{Introducción}

El presente estudio bibliográfico analiza los resultados de la balanza comercial del Ecuador, en el período comprendido entre enero de 2011 a diciembre de 2015, con el objetivo de medir la participación de la balanza comercial respecto al producto interno bruto (PIB), en los períodos mencionados. En la década de 1970 se comenzó con la exportación del petróleo, que es un producto no renovable que se ha convertido en el producto estrella para dar a conocer el país; y al mismo tiempo se constituye en la materia prima de una alta gama de productos, desde inflamables hasta cosméticos, que permitieron, de esta manera, el desarrollo de nuevas ofertas exportables. El sector petrolero constituye una actividad de carácter mundial que regula la fijación de precios, diferenciales de producción y de apropiación de la renta petrolera; actividades que contrastan con los resultados obtenidos en los demás sectores económicos del país (Mateo, 2009).

Ecuador es considerado un país rico en biodiversidad, que mantiene entre sus productos tradicionales de exportación a productos tales como: el petróleo, el cacao, el banano y el café; sin embargo, al presentarse variaciones en el precio del crudo a nivel internacional, se dio inicio al proceso de exportación de productos no tradicionales, con el fin de apalancar la posible caída del precio del producto estrella y mantener una balanza comercial estable que permita el crecimiento del país a la vez que impulsa la matriz productiva.

\section{Balanza Comercial}

Al ser la balanza comercial parte de la balanza de pagos y el lugar donde se registran las transacciones de mercaderías o servicios efectuadas entre los países, el saldo de esta balanza puede representar el crecimiento o decrecimiento económico y social de un país. La balanza comercial se caracteriza básicamente por la comercialización de bienes ${ }^{1}$, si en las negociaciones se añade la comercialización de servicios y transferencias, se concluye que se tiene una balanza corriente ${ }^{2}$ (Fondo Monetario Internacional, 2009).
En cambio, Sullivan y Sheffrin (2003) y McConnell y Brue (2013), señalan que en la balanza de servicios se registran los valores ejecutados de intangibles, entre los que figuran: los servicios profesionales brindados a empresas, los servicios de transporte, el uso de tecnologías, entre otros. Mientras que la balanza de rentas refleja los valores receptados por intereses de inversiones realizadas en instituciones extranjeras. Las transferencias registran los ingresos ocasionados por divisas generadas por envíos del exterior, donaciones y demás rubros que representen ingresos monetarios al país.

En este sentido, Jiménez (2012) destaca que para determinar si la balanza comercial es favorable o no para un país, se la cataloga como positiva cuando las exportaciones hayan superado a las importaciones, lo que se conoce como un superávit comercial y se la cataloga como negativa, al tener un índice más alto de importaciones que de exportaciones, lo que se denomina déficit comercial. Esta situación puede ocasionar una recesión en la producción interna, debido a una reducida producción de materias primas o a la baja calidad de las mismas, dando la oportunidad a productos de afuera para cubrir la producción nacional.

\section{Principales grupos de productos de comercialización en Ecuador}

En el Ecuador, la balanza comercial ha definido su eje de trabajo en dos grupos importantes de comercialización que son los productos tradicionales

$1 \mathrm{Al}$ comercializar bienes entre naciones, se puede determinar que se trata de exportaciones e importaciones, siendo las primeras la entrega o venta de un producto o un servicio bajo la normativa legal y cumpliendo los requerimientos entre los países implicados, así como las condiciones del país vendedor o emisor. En cambio, las importaciones se definen como la inserción al país de bienes o servicios de otras naciones, que no se produzcan en el país y que fortalezcan a la producción interna (Sullivan \& Sheffrin, 2003).

2 La balanza corriente, es parte de la balanza de pagos y un complemento a las importaciones y exportaciones, se consolida con la balanza de servicios, de rentas y de transferencias (Fondo Monetario Internacional, 2009). 
Zlata Borsic Laborde | Karol Benítez Burbano | Nelson García Osorio

Análisis de la evolución de la Balanza Comercial y del Producto Interno Bruto en el Ecuador en el período comprendido entre los años 2011 -2015

y los no tradicionales. En los productos tradicionales exporta: petróleo, banano, camarón, atún y pescado, cacao, café, entre otros. Entre los no tradicionales se encuentran productos tales como: enlatados marítimos, flores, manufactura, fármacos, madera, fruta, harina de pescado, tabaco en rama, jugos y conservas de frutas, manufacturas textiles, manufacturas de cuero y plástico, extracto de aceites y vegetales, manufactura de papel y cartón (Banco Central del Ecuador, 2016).

En las últimas décadas, en Ecuador se han realizado esfuerzos por impulsar a los productos agrícolas, industriales, de manufactura y de artes, proyectándose a la posible pérdida de una fuente de ingresos en los productos tradicionales, como en el caso del petróleo, que al ser un bien no renovable, se puede carecer de este en cualquier momento, además que el nivel de ingresos que este producto genera, depende de la economía externa. De manera que con el apoyo que brinda el país a los productores de bienes no tradicionales, se ofrece la oportunidad a nuevos productores de ofrecer sus bienes en el exterior, además de generar ingresos al presupuesto general del Estado. Sin embargo, pese a los esfuerzos realizados, los productos no tradicionales, no han logrado alcanzar el nivel de ingresos ocasionado por los productos tradicionales, básicamente el petróleo.

\section{Producto Interno Bruto}

Según Callen (2016) "el Producto Interno Bruto (PIB) es una magnitud macroeconómica que permite medir el valor monetario de los bienes y servicios comprados por el consumidor o usuario final, los cuales son producidos en un país o región, en un período determinado, que puede ser un trimestre, un semestre o un ańo, por lo que puede decirse que el PIB representa el tamaño de la economía de un país".

En este sentido, Dawson (2006) señala que el PIB total mide el ritmo en el que aumenta la producción de bienes y servicios y se puede desglosar en términos de la contribución de cada sector de la economía de un país, lo que permite medir el nivel de la salud económica de este, al comparar los resultados anuales obtenidos, con los resultados del año anterior. De manera que si el PIB crece, se estima que la economía del país ha crecido en ese mismo porcentaje respecto del año anterior y viceversa.

Es decir, que cualquier cambio en el PIB, sea que este incremente o disminuya, representa un impacto que recae en todos los aspectos e individuos de una economía. Es por esta razón que el PIB es una de las cifras más básicas que toman en consideración los inversores antes de colocar su dinero en un país, así mismo, es uno de los factores que los economistas utilizan para determinar si una economía está en recesión, término utilizado cuando se presentan dos semestres consecutivos de caída del PIB. Es por ello que se precisa calcular el PIB. El proceso de cálculo es complejo y existen tres métodos para ello: a) el del gasto o de la demanda ${ }^{3}$, b) el del valor agregado o de la oferta ${ }^{4}$ y c) el del ingreso o la renta 5 (Gastón, 2016 ). En el presente trabajo se utilizó el método del gasto para calcular el PIB.

3 De acuerdo con Gastón (2016) en el método del gasto o de la demanda, se realiza la sumatoria de todo el consumo, o sea: los gastos finales que incluyen el consumo de hogares e instituciones sin fines de lucro, más la inversión de las empresas y familias, el gasto en consumo final del sector público, más las exportaciones, menos el consumo de productos importados.

4 El valor agregado se basa en la suma de las ventas u oferta de los productores, para ello se suma el valor de las ventas de los productos de las empresas pero restándole el valor de las materias utilizadas en la elaboración de dichos productos. Los datos de valor agregado de las empresas se agrupan por sectores, tales como: agricultura, ganadería y pesca; industria; construcción y servicios. La suma del valor añadido de cada sector da lugar al valor ańadido bruto total y al restarle los impuestos indirectos netos de subvenciones se obtiene el PIB (Gastón, 2016).

5 Gastón (2016) indica que el método del ingreso o la renta se calcula sumando las rentas de todos los factores que intervienen en la producción. Esta renta sería el dinero que se reciba por concepto del salario, arrendamientos o intereses. 


\section{Relación entre la balanza comercial y el PIB}

A largo plazo la expansión de la economía está restringida por el equilibrio de la cuenta corriente de la balanza de pagos. Por lo tanto, Thirlwall (1979) señala que la condición de equilibrio de la balanza comercial, es que todos sus componentes reflejen tasas de crecimiento, tales como: el volumen de exportaciones y de importaciones, el precio interno, el precio internacional y el tipo de cambio. Por lo tanto, los países llegan a una posición con diferentes grados de uso de su capacidad productiva, "las discrepancias macrodinámicas individuales se ajustan tarde o temprano a través de fluctuaciones del empleo y del producto, de ahí la constelación abigarrada de tasas de crecimiento del PIB per cápita en la economía mundial" (Perrotini, 2002, p. 119), este crecimiento de la economía se conoce como crecimiento diferenciado.

\section{Justificación}

Se efectuó el análisis del comportamiento de la balanza comercial del Ecuador correspondiente a los cinco últimos años (2011-2015), con el pro- pósito de identificar la existencia de superávit o déficit en cada período analizado y así poder establecer su participación en el PIB.

\section{Metodología}

Con el fin de realizar la revisión bibliográfica propósito del presente trabajo, se tomaron en consideración los datos estadísticos obtenidos del Banco Central del Ecuador, así como otra documentación gubernamental publicada y los textos existentes, necesarios para fortalecer criterios. El análisis del PIB se realizó con el enfoque del gasto, con base en miles de dólares del año 2007.

\section{Resultados}

El Banco Central del Ecuador, presenta la información basándose en una economía sustentada en un mercado externo, dando a conocer al mundo las bondades y riquezas del país (Baquero, 2016). Con esta información, se determina el crecimiento del producto petrolero, a la vez que se evidencia la caída de los productos de exportación tradicionales no petroleros y el inicio de

Tabla 1. Evolución de la Balanza Comercial de Ecuador desde el año 2011 hasta el 2015

\begin{tabular}{l|c|c|c|c|c|c}
\hline $\begin{array}{l}\text { Componentes } \\
\text { de la Balanza } \\
\text { Comercial }\end{array}$ & $\begin{array}{c}\text { Ene-Dic } \\
\mathbf{2 0 1 0}\end{array}$ & $\begin{array}{c}\text { Ene-Dic } \\
\mathbf{2 0 1 1}\end{array}$ & $\begin{array}{c}\text { Ene-Dic } \\
\mathbf{2 0 1 2}\end{array}$ & $\begin{array}{c}\text { Ene-Dic } \\
\mathbf{2 0 1 3}\end{array}$ & $\begin{array}{c}\text { Ene-Dic } \\
\mathbf{2 0 1 4}\end{array}$ & $\begin{array}{c}\text { Ene-Dic } \\
\mathbf{2 0 1 5}\end{array}$ \\
\hline $\begin{array}{l}\text { Exportaciones } \\
\text { (15.932.657 }\end{array}$ & 16.835 .682 & 17.756 .018 & 18.226 .379 & 19.120 .101 & 19.155 .407 \\
\hline Importaciones & 18.508 .988 & 19.183 .903 & 19.344 .062 & 20.896 .485 & 22.076 .519 & 20.758 .737 \\
\hline $\begin{array}{l}\text { Balanza } \\
\text { Comercial }\end{array}$ & -2.576 .331 & -2.348 .221 & -1.588 .044 & -2.670 .106 & -2.956 .418 & -1.603 .330 \\
\hline $\begin{array}{l}\text { Tasa de } \\
\text { crecimiento de } \\
\text { las exportaciones }\end{array}$ & & $5.67 \%$ & $5.47 \%$ & $2.65 \%$ & $4.90 \%$ & $0.18 \%$ \\
\hline $\begin{array}{l}\text { Tasa de } \\
\text { crecimiento de las } \\
\text { importaciones }\end{array}$ & & $3.65 \%$ & $0.83 \%$ & $8.03 \%$ & $5.65 \%$ & $-5.97 \%$ \\
\hline
\end{tabular}

Nota. Los datos se encuentran en miles de dólares de 2007. Fuente: Elaboración propia con base en datos estadísticos del Banco Central del Ecuador. (2016). Evolución de la Balanza Comercial. Enero - Diciembre 2015. Quito: Dirección de Estadística Económica. Obtenido de <http://contenido.bce.fin.ec/documentos/Estadisticas/SectorExterno/BalanzaPagos/balanzaComercial/ebc201312.pdf>. 
Zlata Borsic Laborde | Karol Benítez Burbano | Nelson García Osorio

Análisis de la evolución de la Balanza Comercial y del Producto Interno Bruto en el Ecuador en el período comprendido entre los años 2011 -2015

una era de exportación de producos no tradicionales, que desde el Ecuador, se pretende insertar en mercados exteriores. En la Tabla 1 se detalla la evolución de la Balanza Comercial de Ecuador desde el año 2011 hasta el 2015, con datos basados en dólares del año 2007. Cabe destacar que se han incluído los datos del año 2010, porque se necesitaba esa información para poder calcular el monto de la variación en las exportaciones e importaciones para el año 2011.

En la Tabla 1 se aprecia que durante el período de cinco años analizado, la balanza comercial presentó déficit, en parte, debido a que las importaciones se incrementaron respecto de los ańos anteriores, aunque en menor medida que las exportaciones, durante los ańos 2011 y 2012. Se presume que el incremento en las exportaciones se debe más a la subida de los precios internacionales tanto del crudo como de los productos no petroleros, que a un incremento en el volumen de las exportaciones.
De manera posterior, la tendencia se revirtió para los ańos 2013 y 2014, donde el valor de las importaciones fue mayor que el de las exportaciones. Finalmente, durante el año 2015, la Balanza Comercial registró la disminución de la exportación petrolera, pero esta reducción no se debe al volumen, sino a la reducción en el año 2015 del valor unitario promedio del barril exportado de crudo.

Así mismo, se registró decrecimiento en las importaciones $(-5.97 \%)$, lo que podría deberse en gran parte a las salvaguardas establecidas para este año, decisión tomada con la finalidad de fortalecer la empresa nacional (Banco Central del Ecuador, 2016). También se identificó una ralentización de la producción, como por ejemplo, los proyectos de construcción se han reducido y los individuos simplemente, no desean invertir.

Además, la importación de bienes de capital decayó en un 39\% (Cárdenas, 2016). En este mismo

Tabla 2. PIB CON ENFoque Del gasto EN Miles DE DÓlares DE 2007

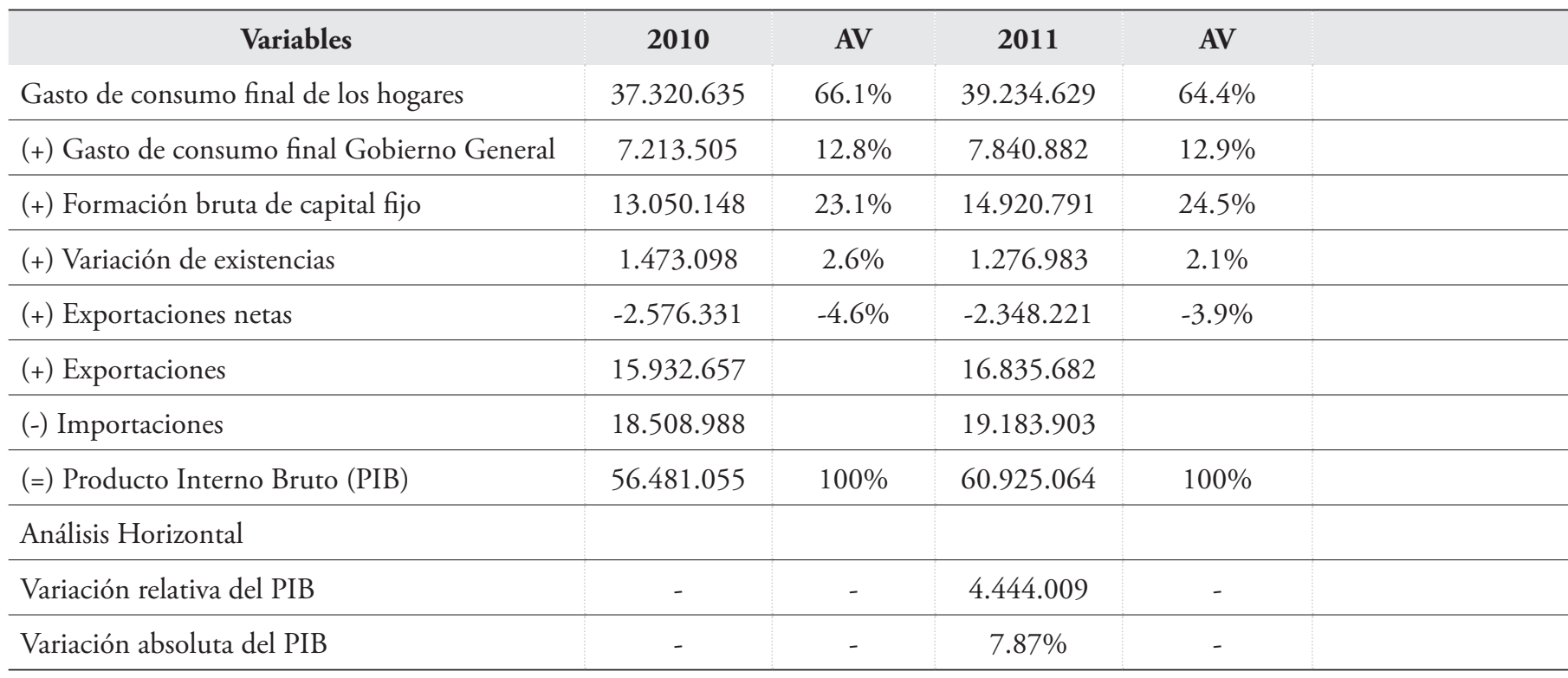


escenario, se analizó la evolución del PIB con base en dólares del año 2007, es decir, a precios constantes, dicha evolución se detalla en la Tabla 2. De igual manera, se realizó el análisis de la variación relativa y absoluta del PIB, así como un análisis vertical de la información, para poder determinar el porcentaje de participación de la balanza comercial al PIB, durante los años 2011 hasta el 2015.

En la Tabla 2 se observa que desde el año 2010, la participación de las exportaciones netas en el PIB ha presentado un valor negativo, el mismo que varía de manera aproximada entre el $2 \%$ y el $5 \%$, situación que conlleva un déficit comercial. De acuerdo con estos resultados, los años que exhibieron el mayor déficit comercial y la mayor participación negativa en el PIB, fueron el año 2013 $(-2.670 .106,-4.0 \%)$ y el año $2014(-2.956 .418$, $-4.2 \%)$. Cabe destacar que para el año 2015 se redujo el monto del déficit, pero no se logró obtener una participación positiva.
A pesar de los resultados negativos de la balanza comercial en los cinco años analizados, entre los ańos 2011 y 2015, el Ecuador tuvo un crecimiento promedio del PIB del $4.41 \%$, hecho impulsado por los altos precios del petróleo e importantes flujos de financiamiento externo al sector público. Esta situación admitió durante ese lapso, un mayor gasto público, tanto en el gasto social como en inversiones emblemáticas en los sectores de energía y transporte. Sin embargo, según Loria (2001) las economías latinoamericanas han crecido a una tasa inferior a su potencial, como efecto de ello se presentan elementos como: acumulación del desempleo, capacidad productiva ociosa y rezagos sociales.

De acuerdo con el análisis vertical realizado con el fin de identificar el peso que tiene cada componente de la balanza comercial en el PIB, en la Tabla 2 se aprecia que durante el período analizado, el principal aporte al PIB corresponde al

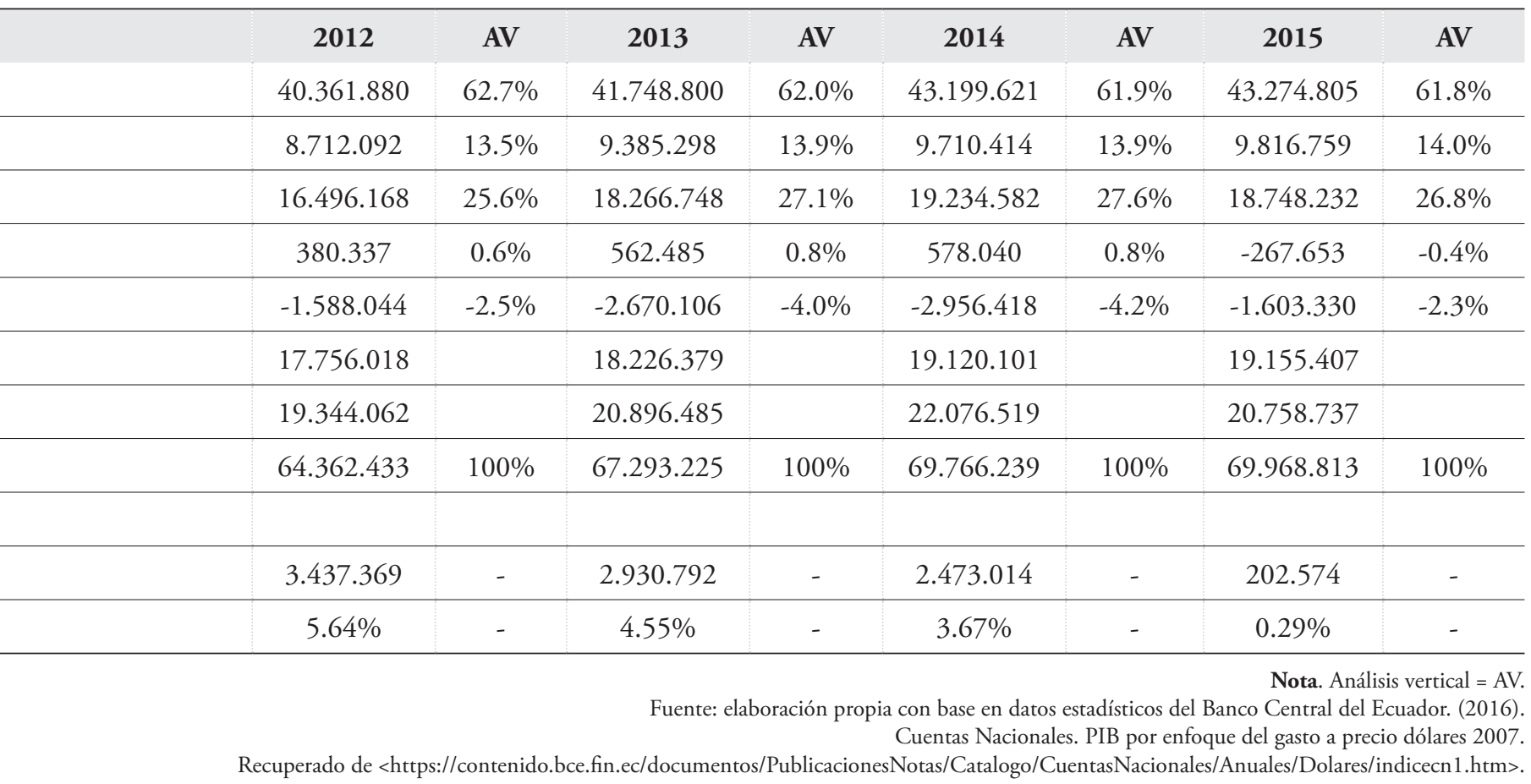


Zlata Borsic Laborde | Karol Benítez Burbano | Nelson García Osorio

Análisis de la evolución de la Balanza Comercial y del Producto Interno Bruto en el Ecuador en el período comprendido entre los años 2011 -2015

gasto de consumo final de los hogares seguido por la formación bruta de capital fijo; en tercer lugar se encuentra el gasto de consumo final del Gobierno General y el cuarto lugar pertenece a la variación de existencias, en cambio, las exportaciones netas presentan un saldo negativo debido a que las importaciones fueron mayores que las exportaciones. Esto implica que durante el período de muestra, la tendencia del PIB ecuatoriano fue determinada por su relación con los valores de la balanza comercial.

$\mathrm{Al}$ analizar las estadísticas macroeconómicas del país (Banco Central del Ecuador, 2016) y de acuerdo con el nuevo escenario mundial, se identificó que para el año 2015, el precio del barril del petróleo ha presentado una caída en el precio internacional, lo que perjudica al presupuesto del Estado. En este orden de ideas, el periódico $E l$ Universo (2015) publicó una entrevista realizada al experto petrolero, Augusto Tandazo, quien señala que la caída en el precio del petróleo está dada por una sobreoferta de crudo, por parte de los principales asociados de la Organización de Países Exportadores de Petróleo (OPEP), los cuales se rehúsan a disminuir su volumen de producción.

En diciembre del año 2014 el precio referencial del crudo WTI ${ }^{6}$ era de USD \$53,27 cuando en enero del mismo año superaba los USD \$ 91, la misma tendencia a la baja se identificó en el crudo ecuatoriano (Oriente y Napo), que a diciembre del 2014 se colocó a USD \$ 48 cuando a inicios de año su precio estaba arriba de los USD \$ 92.

Con los resultados obtenidos en los períodos entre el año 2011 y el 2015, según las proyecciones del Banco Central del Ecuador (2016), existirá un crecimiento del 3,8\% en el año 2016; sin embargo, el Fondo Monetario Internacional (FMI) estima que el Ecuador sufrirá una recesión y su crecimiento no será mayor al 1,5\%, a consecuencia de "las turbulencias financieras, la inminente alza de la tasa de referencia de política monetaria de Estados Unidos, los problemas generados por la transición del crecimiento de China y el reequilibrio de los mercados de materias primas" según la Fundación Salvadoreña para el Desarrollo Económico y Social-Fusades (2015, p. 4).
Además, con la aplicación de las políticas gubernamentales de salvaguardas se espera, fortalecer el mercado interno, mediante la reducción de compras de materia prima al exterior y el fomento de la producción nacional, sin embargo, no se considera que sea un mecanismo de salvamento, puesto que el cerrar mercados puede ocasionar el cierre de relaciones internacionales y eso perjudica al proceso de exportación.

\section{Conclusiones}

- En el Ecuador la balanza comercial ha presentado los últimos cinco años déficit representativos, que no han podido ser cubiertos y que se han arrastrado año tras año, obligando así a contraer deudas y a realizar ventas anticipadas de producciones futuras para poder cubrir los gastos fiscales ocasionados.

- El precio del producto de exportación estrella del Ecuador, presenta una tendencia a la baja que deberá ser compensada con un incremento en la producción petrolera.

- Al ser un país diverso, se debe fortalecer la exportación de productos no tradicionales en el exterior, como un suplemento a los productos que ellos generen, pues al presentar una tendencia a la baja del principal producto de exportación y sus derivados sea en volumen o en precio, se hace indispensable iniciar nuevos retos, en nuevos mercados.

6 El petróleo WTI también conocido como West Texas Intermediate o Texas Light Sweet, es un tipo de petróleo bruto producido en Estados Unidos, que es más ligero que el petróleo Brent producido en Europa, puesto que su composición tan solo contiene un $0,24 \%$ de azufre. Al crudo se lo clasifica como ligero, mediano o pesado dependiendo de la densidad del combustible y como dulce o amargo en función de su contenido de azufre. De manera que el petróleo más preciado es el ligero y dulce, el cual flota en el agua y su contenido de azufre es menor. Tanto el WTI como el Brent son crudos ligeros y dulces. La cotización del WTI es, por lo tanto, una referencia para los precios del petróleo bruto, igual que la del petróleo Brent (La Nación. The Wall Street Journal, 2015). 


\section{Referencias bibliográficas}

- Banco Central del Ecuador. (2013). Evolución de la Balanza Comercial: Enero a Diciembre 2012. Subgerencia de Programación y Regulación. Dirección Nacional de Síntesis Macroeconómica. Quito: Dirección de Estadística Económica.

- Banco Central del Ecuador. (2016). Ecuador inmediato. Obtenido de <http://ecuadorinme diato.com/index.php? module $=$ Noticias $\&$ func =news_user_view $\& i d=136362 \& u m t=$ ecua dor_registra_deficit_en_balanza_pagos_en_segundo_trimestre_del_2010>

- Banco Central del Ecuador. (2016). Evolución de la Balanza Comercial.Enero-Diciembre 2015. Quito: Dirección de Estadística Económica. Recuperado el febrero de 2016, de <http://contenido.bce.fin. ec/documentos/Estadisticas/SectorExterno/BalanzaPagos/balanzaComercial/ebc201312.pdf>

- Banco Central del Ecuador. (2016). PIB por enfoque del gasto a precio dólares 2007. Obtenido de <https://contenido.bce.fin.ec/documentos/PublicacionesNotas/Catalogo/Cuentas Nacionales/Anuales/Dolares/indicecn1.htm>

- Baquero, R. (2016). Actualidad en Ecuador. Obtenidode<http://rtbo99.blogspot.com/2010/ 07/la-balanza-comercial-en-ecuador.html>

- Callen, T. (2016). Gross Domestic Product: An Economy's All. IMF.

- Cárdenas, C. (2016). Balanza Comercial del Ecuador 2016. (C. Cárdenas, Editor) Obtenido de beAnalytic: <http://info.be-analytic. com/balanza-comercial-ecuador-2016>

- Dawson, G. (2006). Economics and Economic Chenge. FT. Prentice Hall.

- El Universo. (2015). El petróleo cae y complica la economía de Ecuador este 2015.

- Fondo Monetario Internacional, F. (2009). Manual de Balanza de Pagos y Posición de Inversión Internacional, sexta edición. Washington D.C. USA.
- Fundación Salvadoreña para el Desarrollo Económico y Social, Fusades. (2015). Informe de Coyuntura Económica. San Salvador: DEC Estudios Económicos.

- Gastón, L. (2016). BBVA. Obtenido de Tres métodos para calcular el PIB: <https://www. bbva.com/es/tres-metodos-calcular-pib/>

- Jiménez, P. (2012). Ruta del conocimiento financiero. En P. Jiménez, Ruta del conocimiento financiero. Quito: Pacheco.

- La Nación. The Wall Street Journal. (2015). El WTI y el Brent cuentan dos historias del crudo. Obtenido de <http://www.lanacion.com. ar/1763119-el-wti-y-el-brent-cuentan-doshistorias-del-crudo>

- Loria, E. (2001). El desequilibrio comercial en México o porqué ahora no podemos crecer a $7 \%$. Momento Económico, N. 113, 16-21.

- Mateo, J. P. (2009). La doble fuga del excedente en Venezuela. En Nacho Álvarez et al. Ajuste y Salario. Las consecuencias del neoliberalismo en América Latina y Estados Unidos. Fondo de Cultura Económica, 111-138.

- McConnell, C., \& Brue, S. L. (2013). Economía (Catorceava ed.). (I. d. Colombia, Ed.) McGraw-Hill.

- Perrotini, I. (2002). La Ley de Thirlwall y el crecimiento en la economía global: análisis crítico del debate. Revista Venezolana de Análisis de Coyuntura, 117-141.

- Sullivan, A., \& Sheffrin, S. (2003). Economics: Principles in Action. Uper Saddle River: Pearson Prentice Hall.

- Thirlwall, A. (1979). The Balance of Payments Constraint as an Explanation of International Growth Rate Differences. Banca Nazionale del Lavoro Quarterly Review, 45-55. 